\title{
СОСТОЯНИЕ ГУМОРАЛЬНОГО ИММУНИТЕТА, КАК ВАЖНЫЙ ПРОГНОСТИЧЕСКИЙ КРИТЕРИЙ ЭФФЕКТИВНОСТИ ПРОГРАММ ЭКСТРАКОРПОРАЛЬНОГО ОПЛОДОТВОРЕНИЯ ПРИ ТРУБНО-ПЕРИТОНЕАЛЬНОМ БЕСПЛОДИИ.
}

\author{
Чехова Юлия Сергеевна \\ ассистент \\ Тюменский государственный медицинский университет, \\ Тюмень, Россия. \\ Соловьёва Светлана Владимировна \\ д.м.н., профессор \\ Тюменский государственньй медицинский университет,
}

Тюмень, Россия.

\begin{abstract}
Аннотация. Изучены показатели гуморального звена иммунитета у клинически здоровых женщин на этапе планирования беременности и у пациенток с трубно-перитонеальным бесплодием в предимплантационном периоде программы ЭКО. Исходный иммунный статус у женщин основной группы не имел патологических отклонений. Выявленные сдвиги в работе иммунной системы у женщин с бесплодием, в зависимости от исходов вспомогательных репродуктивных технологий, носили разнонаправленный характер и могли служить фактором превентивного прогноза, с целью обеспечения более дифференцированного подхода на этапе подготовки и во время проведения ЭКО.

Abstract. The indicators of humoral immunity in clinically healthy women at the stage of pregnancy planning and in patients with pipe-peritoneal infertility in the pre-infantal period of vitro incense fertilization periods are studied. The initial immune status in women of the main group did not have pathological deviations. The identified shifts in the work of the immune system in women with infertility, depending on the outcomes of the auxiliary reproductive technologies, was carried out in a multidirectional nature and could serve as a factor in a preventive forecast, in order to ensure a more differentiated approach at the preparation stage and during extracorporeal fertilization.
\end{abstract}

Ключевые слова: беременность, бесплодие, экстракорпоральное оплодотворение, гуморальный иммунитет. Keywords:Pregnancy, infertility, in vitro fertilization, humoral immunity.

\section{Введение.}

Недостаточная эффективность на современном этапе метода эстракорпорального оплодотворения (ЭКО) диктует необходимость дальнейших исследований, направленных на повышение его результативности [4;6;7]. Большое внимание уделяется поиску иммунологических маркеров лежащих в основе инфертильности, а также имеющих предикторное значение относительно результата ЭКО [8;9;10].

Materials and Methods:

Объектом исследования явились клинически здоровые женщины на этапе планирования беременности (I

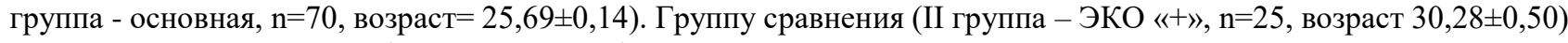
составили пациентки с бесплодием трубно - перитонеального генеза в предимплантационном периоде последующей эффективной программы ЭКО. Третья группа была сформирована из женщин с трубноперитонеальным бесплодием и предстоящей неудачной попыткой ЭКО (III группа - ЭКО «-», n=45, возраст $32,29 \pm 0,32)$. Исследование одобрено Комитетом по этике при ГБОУ ВПО Тюменском ГМУ Минздрава России (выписка из протокола №68 от 08.04.2016 г.).

Для углубленного иммунологического обследования использовали комплекс 1 и 2 уровня по Р.В. Петрову (в лаборатории ГБУЗ ТО «Перинатальный центр» (г. Тюмень)). Оценку иммунологических показателей производили в гепаринизированной крови (25ЕД/мл). Забор крови проводился утром натощак в интервале с 8.00 до 8.30. Комплексное иммунологическое обследование пациентов включало определение концентрации цитокинов (IL-1, IL-2, IL-4, IL-6, IL-10, IFNy, TNF $)$, а также основных классов иммуноглобуллинов (IgA, IgM, $\mathrm{IgG).Статистическая} \mathrm{обработка} \mathrm{полученных} \mathrm{данных} \mathrm{проводилась} \mathrm{с} \mathrm{использованием} \mathrm{пакета} \mathrm{прикладных} \mathrm{программ}$ “Microsoft Office” и “Statistica10”, методами параметрической и непараметрической статистики.

Согласно данным литературы, одну из ведущих ролей в процессах, происходящих в фетоплацентарном комплексе, играют цитокины, которые принимают участие в регуляции нормального развития плода и в реализации механизмов осложненного течения беременности [8]. В ходе нашего исследования у пациенток групп сравнения проанализировано содержание интерлейкинов IL-1 $\alpha$, IL -4, IL- 6, IL - 10, гамма - интерферона (IFN $\gamma$ ) и фактора некроза опухоли (TNF $\alpha)$ (табл. 1).

На этапе предимплантационной подготовки программы ЭКО отмечалось статистически значимое повышение уровня IL-1 $\alpha$ у пациенток II $\left(22,1\right.$ (22,0-22,2) пг/мл; $\left.\mathrm{p}_{1-2} \leq 0,000, \mathrm{p}_{2-3} \leq 0,000, \mathrm{p} \leq 0,01\right)$ и III (99,5 (99,3 -99,6) пг/мл; $\left.\mathrm{p}_{1-3} \leq 0,000, \mathrm{p}_{2-3} \leq 0,01, \mathrm{p}>0,05\right)$ групп, а также провоспалительного TNF $\alpha$ (II $-38,12$ (36,1 - 42,4 пг/мл, $\mathrm{p}_{1-}$ $\left.2 \leq 0,000, \mathrm{p}_{2-3} \leq 0,000, \mathrm{p} \leq 0,000\right)$; III - 92,0 (87,0 - 103,0) пг/мЛ, $\left.\mathrm{p}_{1-3} \leq 0,000, \mathrm{p}_{2-3} \leq 0,000, \mathrm{p}<0,05\right)$, с самыми высокими 
значениями у женщин ЭКО «-». При этом уровень IFN $\gamma$ демонстрировал значительную вариабельность. У женщин I группы, в периоде прегравидарной подготовки, количество IFN $\gamma$ находилось в пределах референсных значений $\left(152,0(149,0-156,0)\right.$ пг/мл; $\left.\mathrm{p}_{1-2} \leq 0,000, \mathrm{p}_{1-3} \leq 0,000, \mathrm{p} \leq 0,000\right)$. Наряду с этим, у пациенток II группы, отмечалось статистически значимое увеличение данного показателя $\left(270,0(261,0-272,0)\right.$ пг/мл; $\mathrm{p}_{1-2} \leq 0,000, \mathrm{p}_{2}$ $3 \leq 0,000, \mathrm{p} \leq 0,01)$. У женщин ЭКО «-» уровень IFN $\gamma$, напротив был значимо снижен $\left(96,0(94,0-105,0)\right.$ пг/мл; $\mathrm{p}_{1-}$ $\left.3 \leq 0,000, \mathrm{p}_{2-3} \leq 0,000, \mathrm{p}<0,000\right)$., на фоне высоких значений IL $-4-49,25(46,2-49,50)$ пг/мл $\left(\mathrm{p}_{1-3} \leq 0,05, \mathrm{p}_{2-3} \leq 0,01\right.$, $\mathrm{p}<0,000) ; \mathrm{IL}-6-110,3(110,0-110,5)$ пг/мл ( $\left.\mathrm{p}_{1-3} \leq 0,000, \mathrm{p}_{2-3} \leq 0,000, \mathrm{p}>0,05\right) ; \mathrm{IL}-10-16,5(15,9-17,7)$ пг/мл $\left(\mathrm{p}_{1-3} \leq 0,01\right.$, $\left.\mathrm{p}_{2-3} \leq 0,000, \mathrm{p}<0,000\right)$. У пациенток с благоприятным исходом ЭКО, на этапе предимплантационной подготовки, отмечалось значимое увеличение противовоспалительного IL- 6 - 55,2 $(55,0-55,4)$ пг/мл $\left(\mathrm{p}_{1-2} \leq 0,000, \mathrm{p}>0,05\right)$ в сравнении с женщинами основной группы.

Таблица 1

Уровень цитокинов крови пациенток групп сравнения

\begin{tabular}{|c|c|c|c|}
\hline 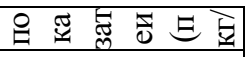 & I группа n=70 & II группа n=25 & III группа n=45 \\
\hline $\mathrm{IL}-1 \alpha$ & $\begin{array}{c}14,0^{* * * \# \#} \\
(13,9 ; 14,3)\end{array}$ & $\begin{array}{c}22,1^{* * * M} \\
(22,0 ; 22,2)\end{array}$ & 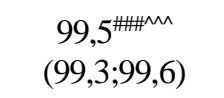 \\
\hline $\operatorname{IFN} \gamma$ & $\begin{array}{c}152,0^{* * * \# \#} \\
(149,0 ; 156,0)\end{array}$ & $\begin{array}{c}270,0^{* * * * M} \\
(261,0 ; 272,0)\end{array}$ & $\begin{array}{c}96,0^{\# \# \text { m }} \\
(94,0 ; 105,0)\end{array}$ \\
\hline TNF $\alpha$ & $\begin{array}{c}18,1^{* * * \# \# \#} \\
(18,0 ; 18,2)\end{array}$ & $\begin{array}{c}38,12^{* * * * \wedge} \\
(36,1 ; 42,4)\end{array}$ & 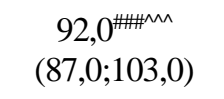 \\
\hline IL - 4 & $\begin{array}{c}43,11^{\#} \\
(43,10 ; 43,12)\end{array}$ & $\begin{array}{c}42,11^{\wedge} \\
(42,0 ; 42,12)\end{array}$ & $\begin{array}{c}59,25^{\# \wedge} \\
(56,2 ; 60,50)\end{array}$ \\
\hline $\mathrm{IL}-6$ & $\begin{array}{c}35,2^{* * * \ldots \# \#} \\
(35,1 ; 35,4)\end{array}$ & $\begin{array}{c}55,2^{* * * M M} \\
(55,0 ; 55,4)\end{array}$ & $\begin{array}{c}110,3^{\#+1 / n \wedge} \\
(110,0-110,5)\end{array}$ \\
\hline IL - 10 & $\begin{array}{c}8,8^{\# \#} \\
(7,5 ; 9,1)\end{array}$ & $\begin{array}{c}9,3^{\text {M }} \\
(9,0 ; 9,6)\end{array}$ & $\begin{array}{c}16,5^{\text {\#\#M }} \\
(15,9 ; 17,7)\end{array}$ \\
\hline
\end{tabular}

Примечание: показатели представлены в виде медианы (Ме) и квартилей (Q1-Q3). Проверка гипотезы о равенстве медианных значений в двух зависимых выборках осуществлялась критерием Вилкоксона (W).

* - статистически значимые различия между I-й и II-й группами: * - $p<0,05, ; * *$ - $p \leq 0,01$; *** - $p \leq 0,000$

\# - статистически значимые различия между I-й и III-й группами: \#- $p<0,05$; \# - $p \leq 0,01$; \#\#\#- $p \leq 0,000$

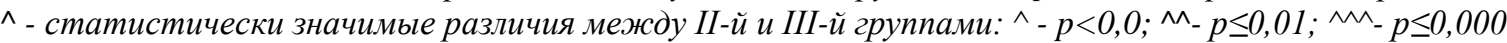

Таким образом, исследование цитокинового статуса на этапе прегравидарной подготовки и в предимплантационном периоде программы ЭКО, выявило повышение концентрации провоспалительных IL-1 $\alpha$ и TNF $\alpha$ у пациенток ЭКО «+», что сопровождалось увеличением содержания IFN $\gamma$, тогда как в группе ЭКО «-» наряду с высокими значениями IL- $1 \alpha$ и TNF $\alpha$, уровень IFN $\gamma$ был значимо снижен. Данный цитокиновый дисбаланс у женщин III группы вероятно обусловлен статистически значимым повышением уровня IL-4, IL-6, IL10, способных оказывать противовоспалительное действие, преимущественно за счёт подавления выработки IFN $\gamma$. Значимое увеличение противовоспалительного IL- 6 у женщин II группы может быть связано с тем, что IL- 6 , играет двойственную роль в развитии воспаления. Являясь по своим свойствам типичным провоспалительным цитокином, он может оказывать и выраженное противовоспалительное действие, ограничивая выработку IL-1 $\alpha$ и $\mathrm{TNF} \alpha[1 ; 2 ; 3 ; 5]$.

При изучении содержания основных классов иммуноглобулинов в сыворотке обследованных пациенток, на этапе подготовки к беременности и в предимплантационном периоде, выявлены статистически значимые изменения. Уровень $\operatorname{IgA}$ снижался у женщин II группы $(1,11 \quad(1,10-1,12)$ г/л; $\left.\mathrm{p}_{1-2}>0,000, \mathrm{p}_{2-3} \leq 0,000, \mathrm{p}>0,05\right)$ и значимо повышался у пациенток ЭКО «-» $\left(1,89(1,87-1,91)\right.$ г/л; $\mathrm{p}_{1-3} \leq 0,000, \mathrm{p}_{2}$ $3 \leq 0,000, \mathrm{p}<0,000)$. Содержание Ig М был значимо выше у женщин программы ЭКО, с наибольшими значениями в III-й группе сравнения $\left(17,29(17,28-17,31)\right.$ г/л; $\left.\mathrm{p}_{1-3} \leq 0,000, \mathrm{p}_{2-3} \leq 0,000, \mathrm{p}<0,000\right)$. Так же у пациенток ЭКО «-» отмечались самые высокие показатели сывороточного IgG - 42,2 $(42,00-42,30)$ г/л $\left(\mathrm{p}_{1-3} \leq 0,000, \mathrm{p}_{2-3} \leq 0,000, \mathrm{p}<0,000\right)$ (табл. 2$)$. 
Показатели гуморального иммунитета у пациенток групп сравнения

\begin{tabular}{|c|c|c|c|}
\hline 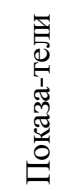 & I группа n=70 & II группа n=25 & III группа n=45 \\
\hline $\begin{array}{l}\operatorname{Ig} \mathrm{A} \\
\text { Г/Л }\end{array}$ & $\begin{array}{c}1,55^{\text {***\#\#\# }} \\
(1,54 ; 1,55)\end{array}$ & $\begin{array}{c}1,11^{\text {***м^ }} \\
(1,10 ; 1,12)\end{array}$ & $\begin{array}{c}1,89^{\# \# \#^{\wedge \wedge \wedge}} \\
(1,87 ; 1,91)\end{array}$ \\
\hline $\begin{array}{c}\text { Ig M } \\
\text { Г/л } \\
\end{array}$ & $\begin{array}{c}1,19^{* * * \ldots \# \#} \\
(1,17 ; 1,20)\end{array}$ & 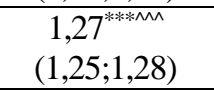 & 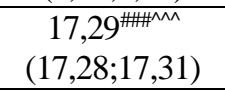 \\
\hline $\begin{array}{l}\operatorname{Ig} G \\
\Gamma / л\end{array}$ & $\begin{array}{c}15,95^{\text {\#\# }} \\
(14,98 ; 15,98)\end{array}$ & $\begin{array}{c}16,0^{\wedge \wedge} \\
(16,56 ; 16,06)\end{array}$ & $\begin{array}{c}42,2^{\# \# \# \wedge \wedge} \\
(42,00 ; 42,30)\end{array}$ \\
\hline
\end{tabular}

Примечание: показатели представлены в виде медианы (Ме) и квартилей (Q1-Q3). Проверка гипотезы о равенстве медианных значений в двух зависимых выборках осуществлялась критерием Вилкоксона (W).

* - статистически значимые различия между I-й и II-й группами: * - $p<0,05$,; ** - $\leq \leq 0,01$; *** - $\leq \leq 0,000$

\# - статистически значимые различия между I-й и III-й группами: \#- $p<0,05$; \#\# - $\leq \leq 0,01$; \#\#\# ${ }^{-} \leq 0,000$

$\wedge$ - статистически значимые различия между II-й и III-й группами: ${ }^{\wedge}$ - $p<0,0 ;{ }^{\wedge \wedge}-p \leq 0,01 ;{ }^{\wedge \wedge}-p \leq 0,000$

Высокие значения $\operatorname{IgM}$ и $\operatorname{IgG}$ в предимплантационном периоде у пациенток программы ЭКО свидетельствуют о избыточной стимуляции иммунной системы с возможным последующим истощением гуморального звена иммунитета. Данные изменения могут служить предиктором неблагоприятного исхода ЭКО $[6 ; 7 ; 9: 10]$

Подводя итог, можно сделать вывод, что исходный гуморальный ответ у женщин основной группы не имел патологических отклонений. Выявленные иммунологические сдвиги у женщин с бесплодием могут усовершенствовать прогноз отрицательных исходов программ ЭКО.

\section{Литература}

1. Каштальян О. А., Пристром М. С. Оценка цитокинового профиля у беременных женщин // Цитокины и воспаление. 2019; 2008 (4).

2. Лихачева В. В. и др. Содержание и прогностическое значение некоторых цитокинов в сыворотке крови и фолликулярной жидкости у женщин с синдромом поликистозных яичников, участвующих в программе эко / / Медицина в Кузбассе. - 2017. - №. 4.

3. Смирнова Т. Л., Портнова Е. В., Сергеева В. Е. Иммунитет и беременность // Вестник Чувашского университета. 2009; 2: 79-85

Сорокина Я.Н. Прогноз результативности программ экстракорпорального оплодотворения у женщин с хроническим эндометритом при трубно-перитонеальном бесплодии: дис. - Московский областной научноисследовательский институт акушерства и гинекологии, 2020.

5. Чистякова Г. Н. и др. Оценка цитокинового профиля при физиологической и патологически протекающей беременности // Цитокины и воспаление. 2019; 2007 (1).

6. Sun D., Capucilli P., Jyonouchi S. Primary immunodeficiency considerations in assisted reproductive technology // The Journal of Allergy and Clinical Immunology: In Practice. - 2019.

7. Guerin L.R., Prins J.R., Robertson S.A. Regulatory T-cell and immune tolerance in pregnancy: a new target for infertility treatment? Hum. Reprod. Update. 2009; 15(5): 517-35.

8. Fasouliotis S. J. Maternal serum levels of interferongamma and interleukin 2 soluble receptor-alpha predict the outcome of early IVF pregnancies / S. J. Fasouliotis, S. D. Spandorfer, S. S. Witkin // Hum. Reprod.- 2014; 6: 1357-1363.

9. Amato G. Serum and follicular fluid cytokines in polycystic ovary syndrome during stimulated cycles / G. Amato, M. Conte, G. Mazziotti // Obstet. Gynecol. - 2013; 6: 1177-1182.

li S. B. et al. The role of immunological testing and intervention in reproductive medicine: A fertile collaboration? /

/ 